\title{
Modal Analysis and Research of Spherical Plain Bearings in Different Materials based on the ANSYS-Workbench
}

\author{
Angang Yan, Liying Yang*, Shouren Wang, Yanjun Wang \\ School of Mechanical Engineering, University of Jinan, Jinan 250022, China
}

\begin{abstract}
The spherical plain bearing was established using the UG of three-dimensional modeling software and imports model into the finite element software ANSYS-Workbench in modal analysis. Under two different materials between GCr15 and Ti44A12Cr8Nb3V0.5B0.5Al2O3 (referred TiAl based alloys), analysis of modal frequencies and mode shapes for spherical plain bearings. The result shows that the deformation of TiAl base alloys spherical plain bearings is significantly less than the amount of deformation of GCr15 spherical plain bearings. So spherical plain bearings modal analysis provide a theoretical basis and reference in the spherical plain bearing applications for the new TiAl base alloy material.
\end{abstract}

KEYWORD: Spherical plain bearing; TiAl based alloys; modal analysis

\section{GENERAL INSTRUCTIONS}

Bearings are critical components of mechanical foundation of the relationship between economic development. They are known as the mechanical "joint", and a spherical bearing (an outer of the inner spherical surface and an inner of the outer spherical surface) is a typical plain bearings, which has a simple structure, small size, large capacity, wide temperature range, long life and other advantages. They have been widely applied to metallurgical rolling equipment, filling equipment, hydraulic turbine, turbine-expander, instrumentation, mining machinery, marine machinery, textile machinery, astronautics and navigation and other fields[1-2]. Especially with the rapid development of the aerospace and automobile industry. They are made more stringent requirements of spherical plain bearings in precision, velocity, sensitivity, life, reliability, temperature, corrosion resistance, etc. [3]. With the use of air and space component of weight loss and weight requirements increasing car, looking for a material both a high tensile strength, high specific strength and high ductility, but also has high temperature resistance, corrosion resistance of new materials become researchers efforts.

In this paper, GCr15 and new materials TiAl based alloys respectively as spherical plain bearing material, the use of UG modeling software for its modeling and modal analysis by ANSYSWorkbench of simulation software and then compare these two materials modal frequencies and mode shapes of spherical plain bearings.

\section{INTRODUCTION THE TIAL BASED ALLOY}

The TiAl based alloy has a light specific gravity and high specific strength, and in the high temperature environment can still maintain a sufficiently high intensity and toughness. It also has good creep resistance and extremely high oxidation resistance, and can replace traditional sliding bearing material tin bronze, zinc alloy and stainless steel, etc. [46].As a new type of high temperature resistance materials, TiAl based alloy material with great potential become light and high-temperature materials in the aerospace, automotive. On the basis of $\mathrm{Ti} 44 \mathrm{Al} 2 \mathrm{Cr} 2 \mathrm{Nb}$ alloys to add $\mathrm{B}$ and hig component $\mathrm{Nb}(8 \%)$ and high hardness ceramic particle nucleation Al2O3, prepared Ti44Al2Cr8Nb3V0.5B0.5Al2O3 new titanium alloy material of antiwear and friction reducing, high temperature resistance and light weight, in its capacity as spherical plain bearing new materials.

\section{ESTABLISH THREE-DIMENSIONAL ASSEMBLY MODEL OF SPHERICAL PLAIN BEARING}

Spherical plain bearings are the research object, and for it to modal analysis. By inner and outer spherical 
plain bearings, whose main structural parameters: diameter $\mathrm{d}$ of $40 \mathrm{~mm}$, outer diameter $\mathrm{D}$ of $68 \mathrm{~mm}$, inner width $B$ of $40 \mathrm{~mm}$, outer ring width $\mathrm{C}$ of $18 \mathrm{~mm}$, spherical diameter $\mathrm{dk}$ of $60 \mathrm{~mm}$ and the ring face outside diameter $\mathrm{d} 1$ of $44 \mathrm{~mm}$. Using $\mathrm{UG}$ of three-dimensional modeling software is modling, three-dimensional solid model of spherical plain bearing, for Figure 1.

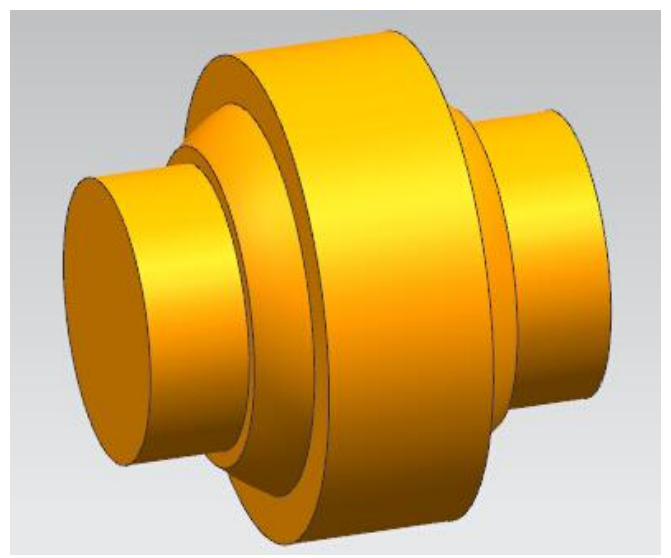

Figure 1. The three-dimensional assembly modle of spherical plain bearing

\section{MODAL ANALYSIS OF SPHERICAL PLAIN BEARINGS UNDER DIFFERENT MATERIALS}

Based on three-dimensional assembly model of spherical plain bearing to establish the modle for simulation analysis, and to add new material, updating data and meshing, etc. Finally, we are in modal analysis for the model modal.

\subsection{Establish simulation model of spherical plain bearing}

The three-dimensional assembly model of spherical plain bearing has some unimportant part features, such as chamfering, oil groove, oil hole. These features in modal analysis of research does not work, and increase the difficulty of analysis and timeconsuming. Therefore, three-dimensional model of spherical plain bearing is simplified to remove chamfering, tanks, and other important parts hole features [7].

Taking into account the ANSYS Workbench and UG three-dimensional design software have seamless connection [8]. So import the UG modle to ANSYS-Workbench, the geometric model generated directly applied to modal analysis.

\subsection{Adding material}

In ANSYS-Workbench, model default material is Structural steel, but this article needs GCr15 spherical plain bearings and TiAl base alloy of the two materials, so the need to add new material in the box Model. The elastic modulus and Poisson's ratio of these two spherical plain bearing materials and other parameters in Table 1 below.

Table 1. The basic parameters of materials

\begin{tabular}{|c|c|c|c|}
\hline Material & $\begin{array}{c}\text { Elastic modulus } \\
(\mathrm{GPa})\end{array}$ & $\begin{array}{c}\text { Poisson's } \\
\text { ratio }\end{array}$ & $\begin{array}{c}\text { Density } \\
(\mathrm{Kg} / \mathrm{m} 3)\end{array}$ \\
\hline GCr15 & 208 & 0.3 & 7800 \\
\hline TiAl Based alloys & 87 & 0.3 & 4180 \\
\hline
\end{tabular}

Add parameters in Table 1 both GCr15 and TiAl based alloys to the ANSYS-Workbench, as shown in Figure 2 below:

\begin{tabular}{|c|c|c|c|c|}
\hline \multicolumn{5}{|c|}{ Properties of Outine Row 3: GCr 15} \\
\hline & A & B & & \\
\hline 1 & Property & Value & & \\
\hline 2 & 7 Density & 7800 & $\mathrm{~kg} \mathrm{~m}^{\wedge}-3$ & 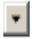 \\
\hline 3 & $\begin{array}{ll}\text { Isotropic Secant } \\
\text { Coefficient of } \\
\text { Thermal Expansion }\end{array}$ & & & \\
\hline 6 & $\exists \square$ Isotropic Elasticity & & & \\
\hline 7 & Derive from & Young's Modulus an... $\quad$. & & \\
\hline 8 & Young's Modulus & $2.07 E+05$ & $\mathrm{MPa}$ & 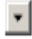 \\
\hline 9 & Poisson's Ratio & 0.3 & & \\
\hline 10 & Bulk Modulus & $1.725 E+11$ & $\mathrm{~Pa}$ & \\
\hline 11 & Shear Modulus & $7.9615 E+10$ & $\mathrm{~Pa}$ & \\
\hline
\end{tabular}

(a) Adding the new material GCr15

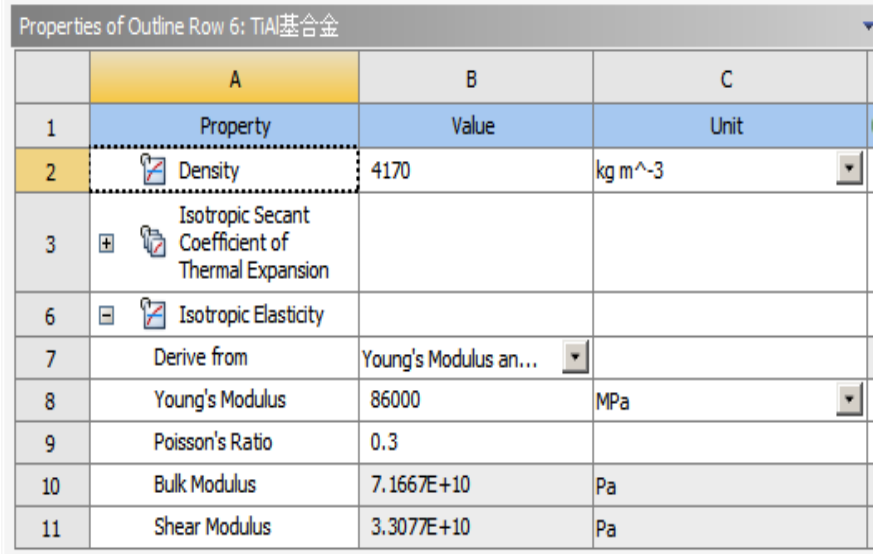

(b) Adding the new material TiAl base alloy

Figure 2. In ANSYS-Workbench to add new material

After adding new material and updating data, then enter Modal-Mechanical and set the mandrel to rigid body.

\subsection{Meshing}

Using automatically partition method in ANSYSWorkbench to mesh the model obtained, after meshing, it has generated 5301 nodes and 841 unit. Meshing model diagram shown in Figure 3: 


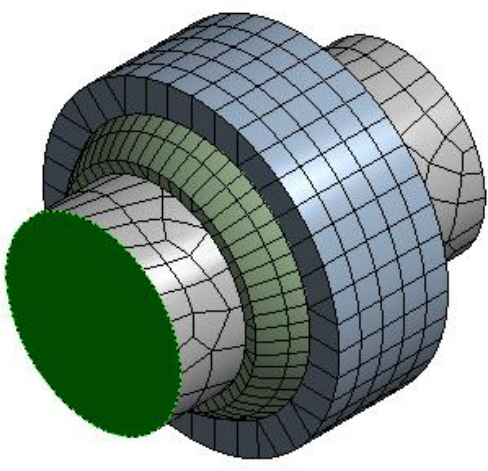

Figure 3. The model of meshing

Divided into a grid for quality testing, this paper to evaluate the distortion degree by Skewness, the closer to 0 indicates that the unit distortion smaller, the closer to 1 indicates more serious distortion. Analysis of the Skewness values obtained in Figure4:

\begin{tabular}{|l|l|}
\hline$\square$ Nodes & 5301 \\
\hline$\square$ Elements & 841 \\
\hline Mesh Metric & Skewness \\
\hline$\square$ Min & .050908750319566 \\
\hline$\square$ Max & .682387492179241 \\
\hline$\square$ Average & .275517728959003 \\
\hline$\square$ Standard Deviation & .15278126135489 \\
\hline
\end{tabular}

Figure 4. The Skewness value

The figure shows: the lowest Skewness value is 0.0509 , the highest Skewness value is 0.6824, average Skewness value is 0.2755 and standard deviation is 0.15278. For automatic division of spherical plain bearings, mesh quality is very good, full compliance with the analytical requirements.

\subsection{Modal analysis of spherical plain bearings}

Modal analysis is the study of the natural frequency of the mechanical system and the main modes. They only related to stiffness characteristics of the structure and the distribution of quality, and unrelated to external factors [9].

In this paper, we do modal analysis of spherical plain bearings under different materials, then compare two materials modal of spherical plain bearings frequencies and mode shapes. Bearings modal analysis of two cases: one is mandrel material is GCr15, bearing inner and outer ring material for $\mathrm{GCr} 15$; another mandrel material is the same as the $\mathrm{GCr} 15$, bearing inner and outer ring material into a new type of TiAl-based alloys.

\section{THE SIMULATION RESULTS ANALYSIS}

Due to low-level natural frequency is very low, so we obtain modal vibration picture of 8-13 under two different materials. Modal distortion figures of bearing inner and outer rings are shown in Figure Fig 5,6 for GCr15 and TiAl based alloys.

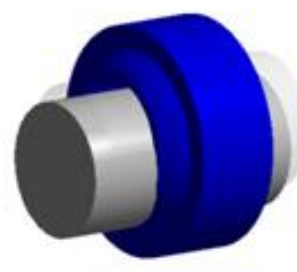

(a) The eighth-order

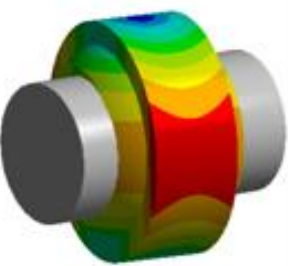

(c) The tenth-order

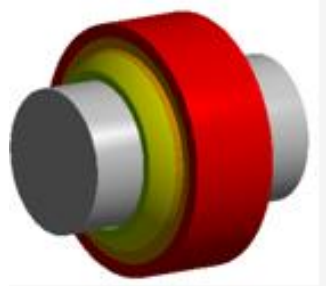

(e) The twelfth-order

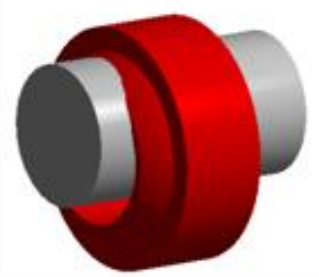

(b) The ninth-order

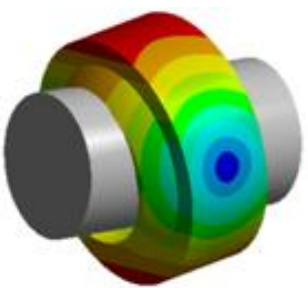

(d) The eleventh-order

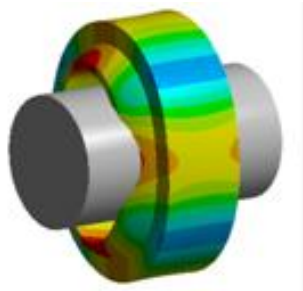

(f) The thirteenth-order
Figure 5, modal shape diagram of the inner and outer rings made of GCr15

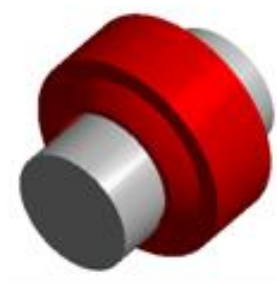

(a) The eighth-order

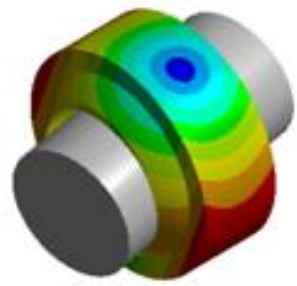

(c) The tenth-order

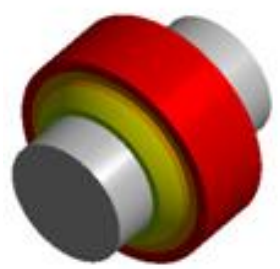

(e) The twelfth-order

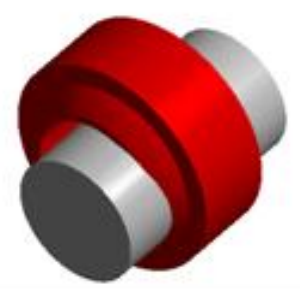

(b) The ninth-order

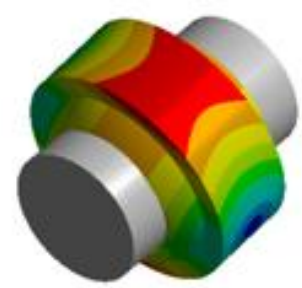

(d) The eleventh-order

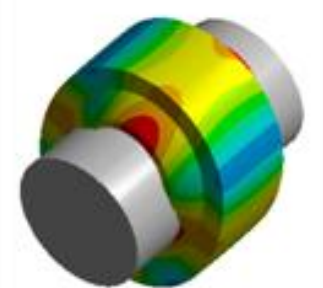

(f) The thirteenth-order
Figure 6, modal shape diagram of the inner and outer rings made of TiAl 
Through we observe and analyze total deformation mode shape diagram of spherical plain bearing in two cases show that: spherical plain bearings deformed of the inner and outer rings made of GCr15 larger than the inner and outer rings made of TiAl based alloys in the same order, and the twelve natural frequencies mainly in $0-14 \mathrm{~Hz}$.It is concluded that TiAl based alloy is more suitable as a new material of spherical plain bearing, and helpful to improve the performance of spherical plain bearings.

\section{CONCLUSIONS}

(1) The establishment of spherical plain bearing of three-dimensional model provides reference to analysis and research for spherical plain bearing in future, and improves the performance of spherical plain bearings, makes spherical plain bearings better to use of the machine.

(2) Through simulation analysis of modal under different materials of GCr15 and TiAl based alloys, draw the total deformation pictures. Compared and analyzed the total deformation pictures, spherical plain bearings deformed of the inner and outer rings made of GCr15 larger than the inner and outer rings made of TiAl based alloys in the same order, so the new TiAl alloy material more suitable applied to the spherical plain bearings.

\section{ACKNOWLEDGEMENTS}

It is a project supported by Shandong Provincial Science \& Technology Developing Plan, China (No.2012GGX10219)

\section{REFERENCES}

[1] Chen Jigang, Yang Yulin, Xia Zhenwei, Cui dripping. Current Status and Development Trends of Forming Technology for Spherical Plain Bearing with One Piece Outer Ring, bearing, 2013, (9): 58-62.

[2] Tang Zhanqi. A Review on the Development of Spherical Plain Bearing, 2008, (7): 71-73.

[3] The "second five" development plan in national bearing industry, 2011.

[4] E.Schwaighofer, B.Rashkova, H.Clemens, A.Stark, S. Mayer. Effect of Carbon Addition on Solidification Behavior, Phase Evolution and Creep Properties of an Intermetallic b-stabilized g-TiAl Based Alloy. Intermetallics, 2014, (46): 173-184.

[5] M.Schloffer, T.Schmoelzer, S.Mayer, E.Schwaighofer, G.Hawranek, F.P.Schimansky. The Characterisation of a Powder Metallurgically Manufactured TNM Titanium Aluminide Alloy Using Complimentary Quantitative Methods. Practical Metallography, 2011, (48): 594-604.

[6] K.P. Rao, A. Vyasb. Comparison of Titanium Silicide and Carbide Reinforced in Situ Synthesized TiAl Composites and Their Mechanical Properties. Intermetallics, 2011, (19): 1236-1242.

[7] Li Kewei, Shen Xuejin, Chen Youguang, Li Ruyan, Cao Lei. Three-dimensional Finite Element Analysis of Radial Spherical Plain Bearings, bearings, 2008, (6): 19-22.

[8] Lv Duanzeng, Dong Jian, Yu Xiaoyang, Zhang Longping. Finite Element Modal Analysis of V8 Engine Crankshaft Based on ANSYS Workbench, mechanical design and manufacturing, 2012, (8): 11-13.

[9] Tian Dongsheng, Hu Ming, Zouping, Liu Yongxian. Modal Analysis of 6-DOF Industrial Robot System Based on ANSYS, machinery and electronics, 2009, (2): 59-62. 